\title{
Johan Galtung e a violência escolar
}

\author{
Johan Galtung and school violence \\ Johan Galtung y la violencia escolar \\ Hans-Georg Flickinger ${ }^{1}$ \\ Professor na Universidade de Kassel, Alemanha
}

Resumo: Neste artigo se propõe um debate sobre a violência e educação com base na teoria de violência defendida por J. Galtung. Na primeira seção são apresentadas as coordenadas principais da referida teoria, nos conceitos de violência direta, estrutural e cultural. Na segunda seção, tendo essa matriz como base, é desenhado um mapa diferenciado da fenomenologia da violência nas instituições da educação para propor, afinal, em uma terceira seção, certas diretrizes facilitadoras do trabalho a realizar em relação à violência nas escolas. Defendo que a violência é um recurso provindo da incapacidade para o diálogo, do desrespeito da autoridade profissional, da transferência de problemas familiares para a escola, do confronto entre diferentes tradições culturais e da presença de regras burocrático-formais em excesso.

Palavras-chave: Violência escolar. Educação. Johan Galtung.

Abstract: This text propose a debate about violence and education based in J. Galtung's theory of violence. First, the main characteristics of said theory are presented in the concept of direct, structural and cultural violence. After and based on this theory I propose one specific features of phenomenology of violence at education institution to propose in third section some facilitation guideline of work to do in relation to violence in school. I defend that violence is one strategy stemmed from incapability dialog, disrespect of professional authority, transfer of family problems to school, conflict among different cultural traditions and presence of excessive of bureaucratic and formal rules.

Keywords: School violence. Education. Johan Galtung.

\footnotetext{
Doutor em Filosofia pela Universidade de Heidelberg; Graduado em Direito em Filosofia pela Universidade de Heidelberg, Alemanha.
} 
Resumen: El texto presenta un debate entre violencia y educación con base en la teoría de defendida por violencia del J. Galtung. En la primera sección se presentan las coordenadas principales de dicha teoría, en los conceptos de violencia directa, estructural y cultural. En la segunda sección, teniendo esta matriz como base, se delinea un mapa diferenciado de la fenomenología de la violencia en las instituciones de la educación para proponer al final en una tercera sección ciertas directrices facilitadoras del trabajo a realizar en relación con la violencia en las escuelas. Defiendo que la violencia es un recurso cuyo origen es la incapacidad para el diálogo, la falta de respecto por la autoridad profesional, de la transferencia de problemas familiares para la escuela, del enfrentamiento entre diferentes tradiciones culturales y de la presencia de normas burocrático-formales en excesos.

Palabras clave: Violencia escolar. Educación. Johan Galtung.

\section{INTRODUÇÃO}

É, de fato, inquestionável o espantoso crescimento da violência em instituições educativas, enquanto meio de solucionar conflitos. Não que faltassem conflitos no passado, ou que se abrisse mão da violência em seu manejo. A situação tem-se, no entanto, agravado devido a uma série de aspectos antes desconhecidos, os quais, aliados aos já existentes, provocam o que se poderia chamar de atmosfera inquietante, em que a sensação do "tudo é permitido" mescla-se ao desamparo das pessoas quanto ao como reagir apropriadamente ao que parece ameaçá-las. Entre esses "aspectos antes desconhecidos", podemos apontar, entre outros, a tecnologia de informática, a migração global, a flexibilização do trabalho e a corrosão da família, os quais influenciam fortemente o que se passa na área da educação. Entre os efeitos da dinâmica sociocultural observa-se, sobretudo, o recurso à violência como provindo da incapacidade para o diálogo, do desrespeito da autoridade profissional, da transferência de problemas familiares para a escola, do confronto entre diferentes tradições culturais e da presença de regras burocrático-formais em excesso. Não pode surpreender, portanto, a exigência crescente de um diagnóstico preciso, capaz de iluminar esse cenário conturbado, como a 
demanda de soluções apropriadas aos problemas que vêm se tornando mais e mais complexos.

Na busca de uma abordagem teórica apta a tornar transparente esse cenário de violência crescente, vale recorrer a debates que, nos anos sessenta e setenta do século passado, voltavam-se à análise de conflitos políticos e de caminhos que levassem à paz. Entre os protagonistas dessas pesquisas e análises temos o norueguês Johan Galtung, matemático, sociólogo e fundador do Instituto para a Pesquisa da Paz, em Oslo. ${ }^{2}$ Ainda que seu trabalho sobre a violência se referisse às políticas internacionais, a tipologia de violência apresentada por ele pode servir-nos de matriz heurística à investigação desse problema no âmbito da educação.

A teoria de violência defendida por J. Galtung está pouco presente na pedagogia brasileira. ${ }^{3}$ Essa é uma lacuna que a primeira seção intenta preencher, apresentando suas coordenadas principais. A seguir, e tendo essa matriz como base, a segunda seção desenhará um mapa diferenciado da fenomenologia da violência nas instituições da educação para propor, afinal, em uma terceira seção, certas diretrizes facilitadoras do trabalho a se realizar em relação à violência nas escolas.

\section{A CONCEPÇÃO DE JOHAN GALTUNG}

Este não é, por certo, o lugar adequado à apresentação, no seu todo, da concepção do sociólogo norueguês. Basta-nos, para o que no momento nos propomos, referir os tipos de violência por ele, primeiro, diferenciados e, a seguir, interligados.

\footnotetext{
2 Johan Galtung, nascido em 1930, pode ser considerado o fundador da pesquisa moderna sobre conflitos políticos e paz. Professor em várias universidades internacionais, ele desenvolveu uma teoria que discute a dinâmica dos processos de violência e os caminhos para a paz.

3 Mais ligado à pedagogia da paz, o Fórum Internacional Cultura da Paz, patrocinado pela Unesco, 2010, em São Paulo, foi um dos eventos mais importantes para tornar a teoria de Galtung mais conhecida na sociologia brasileira. Quanto à pedagogia, esse autor só aparece com a recomendação de certa proximidade com a pedagogia de Paulo Freire, sem ser lembrado no debate sobre questões de violência entre das instituições escolares.
} 
À base de um conceito amplo de violência, Galtung (1998) fala acerca de uma violência direta, uma violência estrutural e uma violência cultural como modos de invasão na vida de pessoas e grupos, no intento de impedir que estes possam realizar seus interesses e aspirações.

Ainda que, à primeira vista, pareça fácil entender o tipo de violência direta, ele é, na verdade, bastante complexo, expressando-se não apenas mediante a agressão física, senão, também, mediante a repressão da liberdade da pessoa, a humilhação psíquica, a negação de recursos necessários à sobrevivência, etc. A violência direta acontece nas relações entre indivíduos ou grupos de pessoas, sem que haja uma intermediação institucional ou estrutural perceptível. Indo desde a lesão física explícita até a ofensa verbal ou a indiferença diante da situação desastrosa de outrem, a violência direta abrange um amplo leque de manifestações. Ela acontece, ou melhor, ela é um feito que fere as necessidades básicas de alguém, tendo sempre, com isso, um autor identificável, que poderá e deverá ser chamado à responsabilidade.

Outra é a situação no que se refere à violência estrutural. A esta, Galtung atribui o caráter de processo, cuja origem é difícil identificar. Igualmente difícil, portanto, seria definir uma responsabilidade pessoal pela situação nela gestada. A violência estrutural é tida como consequência de condições de desigualdade, exploração e injustiça inscritas na sociedade como um todo. Seus efeitos demoram a aparecer e encontram-se, por vezes, ocultos. Não raro, as vítimas sequer percebem as verdadeiras causas de seu sofrimento. Tomemos, por exemplo, a pobreza. Quando uma pessoa não consegue sair da pobreza apesar de se esforçar para isso, é provável que sua situação seja causada por exploração econômica, por marginalização social ou por outros motivos estruturais. Nesse sentido, a violência estrutural representa a intervenção na vida do indivíduo por parte de uma instância ou um poder anônimo, aos quais o indivíduo não tem acesso algum.

Pelo termo violência cultural Galtung (1998, p. 341) entende "aqueles aspectos da cultura, isto é, da esfera simbólica de nosso mundo pensa-se na religião e na ideologia, na língua e na arte, em ciências empíricas e formais -, que podem ser usados para justificar ou legitimar a violência direta ou estrutural." Deve-se à violência cultural o estabelecimento de matrizes e 
convicções que orientam o agir dos membros de uma determinada sociedade; matrizes e convicções essas às quais as pessoas aderem com certa naturalidade culturalmente enraizada, sem dar-se necessariamente conta disso. São princípios da "esfera simbólica" e relativamente estáveis, sofrendo modificações apenas em longo prazo: o fundamentalismo religioso, a crença na racionalidade científica e os preconceitos raciais. Quem quiser entender um caso concreto de violência deverá também "identificar o elemento cultural e mostrar como ele pode ser usado - empírica ou potencialmente - para legitimar a violência direta ou estrutural." (GALTUNG, 1998, p. 325).

A diferenciação dos três tipos de violência serve para fins analíticos. No entanto, o interesse de Galtung vai além da mera análise. Interessado em diagnosticar a dinâmica dos processos violentos, ele acredita na interdependência desses tipos de violência. Daí nasce o seu modelo de relacionamento triangular entre eles; seja qual for o tipo de violência vivida, sua causa não remeterá apenas a esse único tipo. Muito pelo contrário, cada tipo de violência deverá ser interpretado como manifestação de uma constelação específica dos três. Segundo esse modelo, a violência direta, por exemplo, remeteria a impulsos dados pela violência estrutural ou cultural; já a violência estrutural não poderia ser pensada sem sua ancoragem na violência cultural; e, por sua vez, o crescimento da violência direta poderia levar à revisão da violência estrutural, e assim por diante. Enfim, cada tipo de violência experimentado seria entendido unicamente à base de sua interconexão com os demais.

Mencionei anteriormente que o modelo de Galtung resulta das investigações de conflitos na política internacional. São essas pesquisas que lhe dão o material necessário ao desenho dos mapas de percursos em direção à paz política e social. Tendo isso em vista, para a proposta de aqui trabalhar no campo da educação com o modelo triangular de tipos de violência por ele defendido, teremos de considerar a especificidade das formas de violência que ocorrem nesse domínio específico, desafiando igualmente os educandos, os profissionais do ensino e as instituições. Só assim, isto é, à base de sua concatenação institucional e ideológica, conseguiremos identificar as raízes da violência no sistema educativo. 


\section{OS FENÔMENOS DE UIOLÊNCIA NO SISTEMA EDUCATIUO}

Tomando como ponto de partida a matriz proposta por Galtung em seu trabalho, adapto-a, aqui, às experiências pedagógicas, a fim de diferenciar os fenômenos de violência peculiares ao sistema educativo.

\subsection{A UIOLÊNCIA DIRETA}

Para quem se ocupa com o tema educação-violência, salta aos olhos a presença da violência direta no dia a dia do espaço educativo, tanto formal quanto não formal. Ao longo das últimas décadas, a agressividade entre os atores, no palco educativo, vem aumentando espantosamente. São múltiplas e cada vez mais variadas as formas, que dificultam aos jovens estudantes e aos profissionais da área o cumprimento de suas tarefas, a realização de seus interesses e a busca por alcançar suas aspirações. A lista de experiências negativas é longa, entre elas, por exemplo, o bullying as lesões corporais e o enfrentamento de gangues. Experiências estas resultantes de problemas que se manifestam nas relações interpessoais e grupais.

A incapacidade para o diálogo é, sem dúvida, o motivo mais frequente para a violência física direta não somente entre os jovens, senão, também, entre alunos e educadores. No caso de pessoas que, como migrantes estrangeiros, não dominam o idioma do país é, ainda, de algum modo, compreensível que o desamparo dessa incomunicabilidade possa levar à violência corpórea. É, no entanto, espantosa a falta de competência comunicativa na língua materna, hoje observada em grande parte dos jovens socialmente marginalizados. Incompetência que tem várias causas, como a violência no seio da família, a postura passiva à maré alta de informações não domináveis, além da falta de respeito em relação a opiniões diferentes. Não acostumados a argumentar, a posicionar-se e a defender-se de modo comunicativo, as partes do conflito recorrem a meios violentos, no intuito de impor sua posição aos parceiros ou ao grupo. 
Exemplar e, na verdade, uma constante nos debates atuais é o fenômeno do bullying ou mobbing, conceitos hoje usados como sinônimos e internacionalmente reconhecidos por qualificar um tipo de violência coletivo cada vez mais frequente. Diferentemente de conflitos ou brigas ocasionais entre as pessoas, o bullying é caraterizado por contínuos e sistemáticos atos de agressão a uma pessoa. Agressão que pode ser física, verbal ou ambas, dirigindose contra o bem-estar físico e/ou psíquico do indivíduo, e independentemente do status da pessoa - aluno ou professor. Esse comportamento, é claro, surte efeito apenas no momento em que o agressor conta com certa desigualdade de forças a seu favor. $\bigcirc$ que o leva, em geral, a organizar-se em grupo, a fim de intimidar a vítima. No caso específico do cyberbullying é a covardia do anonimato que garante o domínio do agressor, protegendo-o, ademais, de reações imediatas.

Nas formas de agressão direta, praticadas por alunos e profissionais, constam pancadas, sequestros temporários, ações humilhantes, difamações, etc. Não obstante essa variedade, todos os atos de agressão direta têm sua caraterística comum em poderem ser remetidos a indivíduos-autores por eles responsáveis. Uma vez identificados - sejam eles indivíduos singulares, grupos ou gangues -, é possível responsabilizá-los pelo que fizeram de mal. Por isso, na maioria dos casos, a reação pedagógica natural consiste na tentativa de identificar os autores, confrontá-los com seus feitos e puni-los. Cumprido isso, os casos são considerados resolvidos e podem servir de alerta a outros possíveis agressores. Nós veremos, contudo, que tal postura pedagógica pode representar engano, no momento em que analisarmos a influência dos demais tipos de violência - estrutural e cultural - sobre esse primeiro tipo, a violência direta. Com o que passamos à questão da violência estrutural.

\subsection{A UIOLÊNCIA ESTRUTURAL}

○ trabalho educativo realiza-se em organizações de diferentes graus de institucionalização. Desde os diversos tipos de escola até grupos informais na pedagogia social, a variedade organizacional é enorme. Com estrutura 
organizacional própria, cada instituição exerce grande influência no modo de agir de seus integrantes. Tendo isso em vista, ao falarmos acerca da violência estrutural na educação, referimo-nos basicamente às fontes de violência inscritas nos respectivos tipos de institucionalização.

A escola representa, sem dúvida, o modelo institucional mais comum na educação, de modo que o debate sobre a violência deverá se concentrar nas experiências feitas no âmbito dessa instituição. Temos boas razões para supor que a organização tradicional da escola não vem acompanhando as contínuas reformas pedagógicas, senão, pelo contrário, esteja entrando em choque com elas. Uma constelação contraditória que, na verdade, contribui para o aumento espantoso da violência. Com o que se torna necessário tratar dos riscos e efeitos decorrentes do funcionamento atual do tipo tradicional de escola. Referimo-nos, com isso, a sua organização enquanto instituição total.

$\bigcirc$ termo instituição total, cunhado por E. Goffman, quer caracterizar o tipo de organização cujas normas, em larga medida, determinam a vida e o comportamento de seus integrantes. Ritos de iniciação, estruturação de espaço e tempo internos à instituição, determinação de como se vestir e de como viver em sociedade - eis alguns aspectos de um regime que, rigidamente, impõe às pessoas uma lógica a elas, na verdade, alheia (GOFFMAN, 2001). Constrói-se, desse modo, um mundo dentro da instituição, com um mínimo de laços com o que se passa fora dela. Conceber a escola como instituição total significa ver nela uma organização que obriga seus integrantes - alunos e profissionais - a submeter-se a um regime que lhes restringe a liberdade, seja com qual for o grau de rigidez. Ela, com isso, está obviamente a lhes negar opções próprias de vida. E, aqui, temos de perguntar, afinal, o que, basicamente, defende a pedagogia desde o Iluminismo? Não são, acaso, justamente as diretrizes que visam fortalecer a autonomia e a maioridade dos educandos? (FLICKINGER, 2011 ). Salta aos olhos que o ver-se obrigado a adaptar-se ao ritmo escolar tradicional, tendo de viver numa comunidade encenada, lidando com disciplinas consideradas fúteis, entre outras "obrigações", não é, de maneira alguma, compatível com as diretrizes defendidas pela pedagogia moderna. Pois bem, é esta incompatibilidade a causa do que, neste ensaio, chamamos de violência estrutural. 
A tensão existente entre os fins pedagógicos esclarecidos e o modelo institucional (tradicional) de sua realização agrava-se ainda mais devido a um outro aspecto, a saber, o conflito entre a lógica niveladora da instituição burocrática e a missão pedagógica de dar ao educando as melhores condições de desenvolver seu potencial individual. ${ }^{4}$ Quanto maior for o domínio do espírito burocrático em uma instituição escolar, tanto menores serão as chances de os indivíduos exercerem os seus dons pessoais no processo de aprendizagem, e vice-versa. Trata-se aí, em última instância, da oposição entre a lógica de manutenção da ordem institucional e a dinâmica do processo de aprendizagem individual.

De fato, não é fácil chegar a um equilíbrio entre ordem e liberdade. Essa dificuldade está, também, presente em outras unidades educativas, consideradas alternativas em relação à escola. Mesmo organizações consideradas não formais - por exemplo, no ambiente da pedagogia social - exibem aspectos de uma instituição total. Com intensidade variada, vemos também nesse campo rituais de iniciação, hierarquias internas, regras de comportamento, etc., que visam preservar a estabilidade da estrutura grupal. Aliás, também as gangues juvenis, os grupos de motociclistas, as ligas patrióticas estudantis, ou qualquer outro agrupamento com interesse coletivo comprovam essa observação.

Se atentarmos ao cenário desse tipo de violência estrutural, identificaremos, no mínimo, duas exigências básicas: a adaptação forçada do projeto de vida pessoal às pretensões perseguidas pela instituição; e o domínio de uma lógica institucional que restringe ou, no caso extremo, sufoca a autonomia e liberdade de seus integrantes. Seria necessário, portanto, saber "como pensam as instituições." (DOUGLAS, 1986). E, diga-se de passagem, saber como "falam" as instituições. Porque, no mais das vezes, não é nada fácil entender o linguajar institucional, gerando-se frequentemente daí fortes agressões por parte dos submetidos à instituição.

4 Eis a reivindicação famosa de Wilhelm von Humboldt. 


\subsection{A UIOLÊNCIA CULTURAL}

A violência cultural como o terceiro tipo de violência identificado por Galtung é, na pedagogia, até hoje uma incógnita. Fato esse que se explica pela invisibilidade da influência de aspectos culturais no dia a dia da violência escolar, em contrapartida às violências direta e estrutural, que se expressam na relação conflituosa entre pessoas ou na postura de agentes institucionais. Aquele que reflita acerca do fenômeno da violência escolar dificilmente fará conexão entre esse tema e uma ideologia qualquer, como religião, raça, liberalismo político, língua etc., que poderiam levar a atos de violência no âmbito escolar. Vale a pena, por isso, referir algumas das opções ideológicas que exercem forte influência no campo da educação.

As concepções pedagógicas resultam, principalmente, da história cultural de um povo. Trate-se da tradição colonial, do esclarecimento, da política nacionalista, de convicções mitológicas, da crença irrestrita na lógica capitalista ou da pertença a uma determinada língua. Comum a todas essas posições é a crença na sua exclusividade ideológica. Crença essa que se inscreve, naturalmente, também nas diretrizes da formação de futuras gerações. Cada sistema educativo ancora-se na sua respectiva ideologia e busca fortalecê-la, pois ela orienta aquele que a segue, e exclui os que não o fazem. A história cultural, tomada como raiz de uma concepção pedagógica, tem, portanto, um duplo efeito: ao incluir alguns, ela necessariamente exclui outros.

Um caso típico dessa função inerente a seja lá qual for a ideologia é a propagação da assim denominada sociedade de consumo. Na sociedade (neo)capitalista, que não para de lançar incentivos para criar novas demandas, é a capacidade das pessoas em satisfazer tais demandas que decide sobre seu status social. Aquele que não queira ou não consiga acompanhar essa corrida torna-se um outcast, um marginalizado ou tachado de incapaz, incompetente. Às vezes, as próprias políticas de inclusão social recorrem, na sua avaliação dos indivíduos, ao critério de estes terem ou não chance de vir a participar no sistema de consumo. Não surpreende, portanto, o fato de essa ideologia deixar seus traços inclusive no dia a dia da vida escolar. Desde a qualidade das roupas, 
sapatos e outros objetos usados na escola, até o conseguir frequentar eventos culturais badalados, ou a aquisição da última geração de um computador, é sobretudo a capacidade de consumo que se torna o critério decisivo de reconhecimento social entre os alunos.

Uma outra causa da violência escolar é a ideologia racial. A raça é usada, muitas vezes, como critério de definição da pertença social dos indivíduos. Classe social essa que, por sua vez, é vista como condição de participação em certas atividades escolares, como nos benefícios vindos da instituição. Não por acaso o debate recente sobre cotas que garantam a integração de minorias raciais de desprivilegiados no sistema educativo leva a conflitos ideológicos de difícil solução, em razão de que qualquer que seja a solução jurídica encontrada, ela é passível de ser interpretada como reforço à discriminação racial.

Fala-se pouco acerca da forte influência do princípio de subsidiariedade nas instituições da educação. Ideologicamente ancorado na história da secularização, esse princípio serve, até hoje, para legitimar a prevalência das diretrizes defendidas pelos detentores do poder religioso nas instituições de educação. Essa questão tem importância não apenas para entender o papel histórico da Igreja Católica na construção do sistema educativo no Brasil, senão, também, para entender a ação cada vez mais abarcadora de uma multiplicidade de novas Igrejas, as quais exigem, igualmente, a primazia de suas próprias normas ético-morais no sistema educativo. Como se isso não bastasse, a situação agrava-se na medida em que essas novas igrejas assumem uma postura fundamentalista. Um caso exemplar para os conflitos ideológicos que se fazem presentes nas instituições escolares afetadas por elas é aquele da disputa entre evolucionismo e criacionismo em certas disciplinas científicas que queiram ser seriamente ministradas.

Falando-se acerca da violência cultural como marco de influência na educação é impossível ignorar os efeitos da sociedade liberal como sociedade de concorrência. Quem não entra no seu ritmo vê-se logo deslocado do centro para as margens. Tanto em nível econômico quanto em relação às chances de participação na vida social e cultural, o princípio de concorrência favorece a segregação social, que produz vencedores e vencidos, ricos e pobres, porta- 
vozes e emudecidos. $\bigcirc$ espírito de concorrência está presente em todas as relações e atividades sociais, não poupando, é claro, o sistema educativo. Destacar-se em meio aos demais, vencer o(s) concorrente(s), é palavra de ordem. Isso, porém, não apenas decide acerca de uma futura integração no mercado de trabalho, mas promove, infelizmente, o que Sennett (1999) denuncia como "corrosão do caráter".

Há, como se vê, um amplo leque de referenciais ideológicos cujo incentivo à violência concreta - direta e estrutural - no sistema educativo tem de ser urgentemente revelado. Para tanto, na nossa tentativa de apontá-lo recorreremos agora à concepção triangular de Galtung.

\subsection{A INTERDEPENDÊNCIA DOS TIPOS DE UIOLÊNCIA}

Para entendermos a violência praticada no sistema educativo, temos de ter presente os estragos que a violência cultural provoca sobretudo nas sociedades com crescente caráter intercultural. A migração em nível global vem criando cenários de conflitos ideológicos que topam com um sistema educativo despreparado, incapaz de reagir adequadamente. Lembro de jovens migrantes que - com problemas relacionais não apenas em decorrência da origem cultural diferente, senão também com dificuldade de expressão verbal, por falta de conhecimento da língua -, não encontrando saída no diálogo, recorrem à força física para dar solução aos inevitáveis conflitos. Do mesmo modo, o profissional em cuja formação predomina a ideologia da disciplina e da ordem, quando do conflito com os alunos não hesita em reagir à base da repressão e punição física ou psíquica. Um outro exemplo refere-se àqueles grupos de alunos de convicções fundamentalistas: incapazes de reflexão, enfurecemse com qualquer resistência às suas crenças religiosas e, para defendê-las, não hesitam em desrespeitar direitos humanos reconhecidos, agredindo com violência os colegas. Pode também acontecer de a instituição escolar reagir ao crescimento da violência direta entre os alunos mediante meios repressivos, igualmente violentos. Outro fator a considerar no sistema educativo vigente é a existência (ainda) de instituições ideologicamente comprometidas, que 
insistem na obediência às suas próprias diretrizes religiosas; estas nem sempre encontram eco nos educadores, que se veem ameaçados profissionalmente. Também aí o potencial de conflito entre as partes é considerável.

Em todos esses exemplos há algo em comum, a saber: a violência aí praticada é causada não somente pelo destempero de alguns indivíduos ou grupos, mas também pela influência de estruturas institucionais específicas e por referenciais ideológico-culturais que subjazem à atuação dos integrantes do sistema educativo. Não raro, os três tipos de violência sustentam-se mutuamente. Assim, a violência direta entre jovens pode ser uma rebelião contra as regras da instituição educativa em que se encontram; por sua vez, a própria instituição poderá estar sendo obrigada a fazer obedecer às diretrizes ideológicas de seu regedor. Pode acontecer, também, de uma determinada ideologia - por exemplo, uma tradição cultural - impelir os jovens a lançar mão de violência física como vingança pelo que acreditam ter sido uma ofensa sofrida. Também é possível que os atos violentos exercidos entre representantes de tradições culturais distintas sejam um sinal de desamparo diante da própria impotência em satisfazer expectativas inerentes à ideologia com a qual tais agentes estão comprometidos. Em todo caso, tratando-se de constelações extremas, a violência direta, praticada entre grupos, pode levar a mudanças de diretrizes institucionais ou mesmo de sua base ideológica.

É importante, de qualquer maneira, enfatizar que, seja qual for o ponto de partida da análise feita sobre a violência - direta, estrutural ou cultural - sempre foi confirmada a interdependência desses três tipos diferenciados por Galtung. Assim, é possível referir que, sem o seu reconhecimento, a violência escolar ficaria incompreensível, mantendo-se sobretudo oculta a dinâmica que a alimenta. Por isso, ao trazer à tona, em suas investigações, a violência cultural como referencial legitimador da violência, tanto direta quanto estrutural, Galtung inaugura uma via essencial de compreensão também para o que nesse sentido ocorre, especialmente hoje, no sistema educativo. Ao mostrar que, ao desrespeitar as experiências histórico-culturais que as sustentam, as ideologias tornam-se fontes de poder, de autoridade falsa e de violência cultural, ele nos descortina um horizonte de reflexão do qual não podemos abrir mão no campo pedagógico. 


\section{O MANEJO DA UIOLÊNCIA NO SISTEMA EDUCATIUO - UMA PROPOSTA}

A aplicação do modelo de Galtung na análise da violência, observada na área da educação, possibilita-nos propor também modos de como reagir as suas manifestações, que vêm se mostrando alarmantes. Para intervir na discussão desse problema, proporei, finalmente, alguns passos de procedimento.

Em primeiro lugar, parece-me óbvio que só se poderá avaliar devidamente a violência que acontece no sistema educativo mediante uma inicial diferenciação dos tipos de violência que aí ocorrem. Na maioria dos casos trata-se, sem dúvida, da violência direta, cometida por pessoas ou grupos: lesão corporal, ritual de iniciação violento pelo peer-group, falsas acusações, etc. A violência, contudo, pode brotar também da instituição, quando esta, submetida ela mesma a normas e diretrizes rígidas, a promove. É o que ocorre, por exemplo, quando do corte de benefícios materiais, da imposição incondicional da hierarquia ou de um tratamento desigual. Acontece não raro, também, que a violência seja praticada e legitimada em nome de uma ideologia qualquer de cunho radical. $\bigcirc$ fundamentalismo religioso, a ideologia darwinista do mais forte, a fé na lógica do mercado, a utopia igualitária - eis pelo menos quatro referenciais culturais com potencial de promover a violência.

A clareza buscada em relação aos tipos de violência reinante marca, portanto, o primeiro passo no sentido de tornar transparente a complexidade desse cenário, além de evitar que falemos uns com os outros sem uma base de compreensão adequada. Um segundo passo deve ser feito mediante a tematização dos estímulos, que poderiam levar o agressor a recorrer à violência. Com isso se estará investigando as origens das motivações que desembocam nos atos violentos, inclusive aquelas da possível influência institucional e ideológica, indicadas anteriormente. Essa será, talvez, a fase mais difícil da investigação, por depender da colaboração dos próprios envolvidos. Estes deveriam, para tanto, estar não só dispostos a dela participar, senão ter ainda abertura suficiente para dialogar. Se é, por exemplo, verdade que parte da violência direta advém da dificuldade de se expressar também verbalmente, 
por parte dos agressores, e que o linguajar pedagógico e burocrático dificulta o entendimento dos jovens, a solução poderia estar na ampliação dos meios de comunicação. As chances de um diálogo aberto, que leve à compreensão do que se esconde por trás dos feitos violentos, depende da oferta de espaços comunicativos também não verbais, como a música, a dança, o desenho, a encenação de papéis, as apresentações teatrais, etc. Com tais recursos, a escola dá aos agentes da violência a chance de perceber e reconhecer os motivos que os levam a agir violentamente. Isso poderia levá-los a refletir de modo crítico sobre si mesmos, a ponto de conseguir avaliar a própria responsabilidade, e, portanto, a rever a postura anterior.

A partir de um diálogo aberto, seria possível resolver, ainda, outro aspecto importante da violência: aquele da distribuição das responsabilidades. Uma vez identificados os tipos de violência e os motivos que levam a ela em um qualquer cenário educativo, esclarece-se, igualmente, a interdependência entre eles. Com isso, é possível estabelecer, igualmente, o grau de responsabilidade a ser atribuído aos atores em jogo. Assim, o neófito que usasse de violência física para se defender da brutalidade de um ritual de iniciação qualquer, praticado por veteranos, não poderia ser responsabilizado integralmente por esse seu ato; naturalmente, desde que não tivesse tido outro recurso no momento da ação. $\bigcirc$ mesmo vale para o aluno que, fixado nos preceitos de sua religião, lançasse mão da violência ao sentir o profeta dela difamado em sala de aula. É claro que, nestes casos, parte da responsabilidade pela violência praticada caberia a falhas estruturais da instituição e à ideologia que a sustenta. Em tais situações, seria sempre necessário tematizar, sim, pôr em diálogo justamente essas responsabilidades, a fim de conter a espiral de violência. Foi a isso que nos referimos antes (item 2.1) ao indicar que nem sempre a punição do agente da agressão direta seria a solução correta. Em caso algum, na verdade, devese desconsiderar a interação dos três tipos de violência apontados por Galtung.

Seria, ainda assim, ingênuo pensar que as considerações anteriores, feitas a partir do modelo de Galtung, pudessem erradicar a violência que se observa, hoje mais do que nunca, nas instituições educativas. Eu mesmo acredito, no entanto, que elas possam trazer mais luz a essa problemática que, na verdade, preocupa não somente a pedagogia, mas a sociedade como um todo. 


\section{REFERÊNCIAS}

DOUGLAS, M. How Institutions think. Syracuse: Syracuse University Press, 1986.

FLICKINGER, H.-G. Autonomia e Reconhecimento: dois conceitos chave da formação. Revista Educação, Porto Alegre, v. 34, n. 1, p. 7-12, jan./abr. 2011.

GALTUNG, J. Frieden mit friedlichen Mitteln. Opladen: Verlag für Sozialwissenschaften, 1998.

GOFFMAN, E. Manicômios, Prisões e Conventos. Tradução Dante Moreira Leite. 7. ed. São Paulo, 2001.

SENNETT, R. A corrosão do caráter. Tradução Marcos Santarrita. Rio de Janeiro: Editora Record, 1999.

Recebido em: 17 de outubro de 2017 Aceito em: 18 de junho de 2018

Endereço para correspondência: Mönchebergstraße 19, 34125 Kassel, Alemanha; zarameurersl2@gmail.com 